\title{
Potential Use of Salivary Biomarkers to Evaluate the Hepatic Status in Cancer Patients under Chemo- and Radiotherapy
}

\author{
Archana A Gupta ${ }^{1}$, Pooja Jaisinghani ${ }^{2}$, Shivaranjhany Sivakumar ${ }^{3}$, Shankargouda Patil ${ }^{4}$, A Thirumal Raj $^{5}$
}

World Journal of Dentistry (2019): 10.5005/jp-journals-10015-1641

Postsurgical chemotherapy and radiotherapy in cancer patients can have detrimental effects, especially in cases wherein cancer has severely compromised the patients' health. The side effects of the chemotherapy and radiotherapy on the patient can be assessed by the abnormal variations noted in the serum and salivary concentration of several known enzymatic biomarkers. Hepatotoxicity (a common side effect of chemo and radiotherapy) is indicated by an abnormal serum concentration of lactate dehydrogenase (LDH), aspartate aminotransferase (AST), and alanine aminotransferase (ALT). Green et al. examined the serum ALT levels in 2751 childhood cancer survivors (CCS). Anticancer therapeutic medications in CCS (including radiotherapy) were shown to result in a significant hepatic injury, as evidenced by the increased serum ALT concentrations. ${ }^{1}$ On the basis of the results, the authors emphasized the role of serum ALT in monitoring the hepatic status in cancer survivors.

Estimation of serum ALT levels, although proved to be reliable, involves periodic invasive sampling, which, on the long run, may not be compatible, especially in a debilitated state as in cancer patients. Use of the saliva (instead of the serum) for ALT estimation in cancer patients could significantly reduce the patient's discomfort. Yamaguchi et al. compared the serum and salivary ALT levels between healthy patients and patients diagnosed with a liver disease. The salivary ALT levels were found to be only one-third of the serum ALT levels. Although salivary concentration of ALT was relatively less than that of serum, a significant difference was noted between the salivary ALT levels of the healthy and that of the liver-disease patients. The salivary ALT activity was higher in liver-disease patients than in the healthy controls. On the basis of their results, they concluded that similar to those of the serum, salivary levels of ALT can also be used to distinguish healthy adults from liver-disease patients. ${ }^{2}$

Despite promising results, salivary ALT levels have shown to vary in conditions other than a hepatic injury. Diabetes and periodontitis have shown to significantly alter the salivary ALT levels, and thus cancer patients with higher salivary ALT levels must also be assessed for other potential confounders. ${ }^{3-6}$ To conclude, although further studies are required to confirm the correlation between salivary ALT levels and the hepatic status, there is sufficient evidence to suggest that estimating ALT levels of the saliva could be a potential noninvasive method to monitor the hepatic status in cancer patients, especially during radio and chemotherapy.
${ }^{1}$ Department of Oral Pathology and Microbiology, Dr DY Patil Dental College and Hospital, Dr DY Patil Vidyapeeth, Pune, Maharashtra, India ${ }^{2}$ Department of Radiology, Government Medical College, Miraj, Maharashtra, India

${ }^{3}$ Sapphire Primary Care, Faculty of Dentistry, Universiti Teknologi MARA, Ministry of Higher Education, Selangor, Malaysia

${ }^{4}$ Department of Maxillofacial Surgery and Diagnostic Sciences, Division of Oral Pathology, College of Dentistry, Jazan University, Jazan, Kigdom of Saudi Arabia

${ }^{5}$ Department of Oral Pathology and Microbiology, Sri Venkateswara Dental College and Hospital, Chennai, Tamil Nadu, India

Corresponding Author: A Thirumal Raj, Department of Oral Pathology and Microbiology, Sri Venkateswara Dental College and Hospital, Chennai, Tamil Nadu, India, Phone: +91 8122627810, e-mail: thirumalraj666@gmail.com

How to cite this article: Gupta AA, Jaisinghani $P$, et al. Potential Use of Salivary Biomarkers to Evaluate the Hepatic Status in Cancer Patients under Chemo- and Radiotherapy. World J Dent 2019;10(3):165.

Source of support: Nil

Conflict of interest: None

\section{References}

1. Green DM, Wang M, et al. Serum ALT elevations in survivors of childhood cancer. a report from the St. Jude Lifetime Cohort Study. Hepatology 2018;69(1):94-106. DOI: 10.1002/hep.30176.

2. Yamaguchi M, Kawabata $Y$, et al. Proposal of Noninvasive Liver function measurement method via Saliva. IEEJ Trans SM 2003;123(11):483-486. DOI: 10.1541/ieejsmas.123.483.

3. Chambers DA, Crawford JM, et al. Aspartate aminotransferase increases in crevicular fluid during experimental periodontitis in beagle dogs. J Periodontol 1984 Sep;55(9):526-530. DOI: 10.1902/ jop.1984.55.9.526.

4. Imrey PB, Crawford JM, et al. A cross-sectional analysis of aspartate aminotransferase in human gingival crevicular fluid. J Periodontal Res 1991 Mar;26(2):75-84. DOI: 10.1111/j.1600-0765.1991.tb01629.x.

5. Nakamura T, Kido J, et al. The association of calprotectin level in gingival crevicular fluid with gingival index and the activities of collagenase and aspartate aminotransferase in adult periodontitis patients. J Periodontol 2000 Mar;71(3):361-367. DOI: 10.1902/ jop.2000.71.3.361.

6. Malicka B, Skoskiewicz-Malinowska K, et al. Salivary lactate dehydrogenase and aminotransferases in diabetic patients. Medicine (Baltimore) 2016 Nov;95(47):e5211. DOI: 10.1097/ MD.0000000000005211.

(O) The Author(s). 2019Open Access This article is distributed under the terms of the Creative Commons Attribution 4.0 International License (https://creativecommons. org/licenses/by-nc/4.0/), which permits unrestricted use, distribution, and non-commercial reproduction in any medium, provided you give appropriate credit to the original author(s) and the source, provide a link to the Creative Commons license, and indicate if changes were made. The Creative Commons Public Domain Dedication waiver (http://creativecommons.org/publicdomain/zero/1.0/) applies to the data made available in this article, unless otherwise stated. 